\author{
Pergeseran Pola Kepemimpinan Kiai \\ dalam Mengembangkan Lembaga Pesantren
}

\author{
Mahfudz Sidiq ${ }^{1}$ \\ Universitas Negeri Jember \\ mahfudzsidiq@gmail.com
}

\begin{abstract}
The development and sustainability of Islamic Boarding School are strongly influenced by the regeneration of the leadership of kiai as a successor of the vision and mission, depending upon their disciplines. Regeneration of the leadership of kiai often occurs on the basis of lineage to maintain and respond the developmental and institutional dynamics in the boarding school. The research is intended to analyze and discover the leadership patterns of kiai, the shifting patterns of the leadership, and the impact of the shift towards the development of the institutions.

This study is phenomenological. The data collection techniques employed were observation, in-depth interviews, and documentation. The data analysis procedures were data reduction, data display, and conclusion. Tringualation was used to check the data validity, credibility, transferability, dependability, and confirmability.

The findings of the research reveal the following results. Firstly, the pattern of the leadership of kiai is preserving and maintaining lineage or dzurriyyah (leader is born). The characteristics of the leadership of kiai are paternalistic, charismatic, pseudo-democratic, and transcendent-transformative. Secondly, the shifting patterns of the leadership of kiai are maintaining direct dzurriyah, direct and closest dzurriyyah, and indirect and closest dzurriyyah. The patterns are based on the following principles: a) capable to maintain knowledge and the characteristics of the boarding school, b) able to maintain the values of the boarding schools and families (dzurriyyah), c) able to maintain the values and patterns of leadership characteristics which are paternalistic, charismatic, pseudodemocratic, and transcendent-transformative, and d) finally, able to maintain the institutional characteristics of the boarding schools which are salafiyah, salafiyah-khalafiyah, and khalafiyah. Thirdly, the impacts of the leadership shift of kiai are as follows. a) the leadership pattern is more open and accepts value changes. b) Diversity of institutional models occurs from salafiyah, salafiyahkhalafiyah, and khalafiyah. c) the models of institutional buildings are from wood and bamboo to modern buildings. d) the quality of human resources is in the forms of expertises religious knowledge and science. e) the management of santri is from traditional to classical management models, and f) the outputs or
\end{abstract}

\footnotetext{
${ }^{1}$ Dosen Progran Studi Ilmu Kesejahteraan Sosial, Fakultas Ilmu Sosial dan Ilmu Politik Universitas Jember 144 | Falasifa, Vol. 11 Nomor 1 Maret 2020
} 


\section{Mahfudz Sidiq}

graduates involve in the works for the religious instution and community services in his environment.

Keywords: Shifting Patterns, Leadership of Kiai, Institution, Islami Boarding School.

\section{PENDAHULUAN}

Pesantren sebagai lembaga pendidikan Islam tertua di Indonesia telah menunjukkan kemampuannya dalam mencetak kader ulama dan berkontribusi besar dalam mencerdaskan masyarakat Indonesia. Selain tugas utama tersebut, pesantren menjadi pusat kegiatan pendidikan yang berhasil menanamkan semangat kewirasuastaan, dan semangat berdikari yang tidak menggantungkan diri kepada orang lain. Di pesantren ditanamkan pula semangat patriotik membela tanah air dan agama, sehingga tidak mengherankan apabila dalam masa penjajahan Belanda dan Jepang sering timbul pemberontakan yang dipimpin oleh kalangan pondok pesantren. ${ }^{2}$

Kepemimpinan pesantren memiliki ciri dan sifat terpuji yang harus dimiliki seorang kiai. Sejatinya menurut Abdulgani (dalam Abdurrahman), ${ }^{3}$ kepemimpinan diperlukan adanya sifat kelebihan dari yang memimpin, sifat tersebut meliputi: 1) kelebihan akal pikiran, 2) kelebihan rohaniah, dan 3) kelebihan jasmaniah.

Sistem pengakuan sebagai kiai telah mengembangkan tradisi bahwa keturunan mereka (terutama anak atau cuculaki-laki) memilki kesempatan besar untuk menjadi kelompok kiai. ${ }^{4}$ Selain lekat dengan nilaii agama, calon pemimpin pesantren memiliki modal kehidupan kultural pondok pesantren. Ali ${ }^{5}$ mencirikan kehidupan kultural pesantren tradisional dengan mengidentifikasi beberapa pola seperti; 1) adanya hubungan akrab antara kiai dan santri; 2) tradisi ketundukan dan kepatuhan santri terhadap kiai; (3) Pola hidup sederhana (zuhud); 4) kemandirian atau independensi; 5) kerkembangnya tradisi tolong-menolong dan suasana persaudaraan; 6) disiplin ketat; dan 7) berani menderita untuk mencapai tujuan.

\footnotetext{
${ }^{2}$ Abd. Rahman Shaleh, dan kawan kawan, 1987/1988. Pedoman Pembinaan Pondok Pesantren, Jakarta: Proyek Pembinaan dan Bantuan Kepada Pondok Pesantren Ditjen Pembinaan Kelembagaan Agama Islam, Departemen Agama RI. p. 3

${ }^{3}$ Roeslan Abdulgani, 1985. (dalam) Majalah Pondok Pesantren, Jakarta: P3M, No. 1/Vol.11. p. 14

${ }^{4}$ Zamakhsyari Dhofier, 1985. Tradisi Pondok Pesantren: Studi Tentang Hidup Kiai, Jakarta: LP3ES, p. 68. Untuk selanjutnya Zamakhsyari Dhofier, 1985. Tradisi ........

5 A. Mukti Ali, 1999. p.15. Lihat pula, A. Mukti Ali, no. 2/Vol. IV/1987. Meninjau Kembali Pondok Pesantren sebagai Lembaga Pendidikan Ulama, dalam Majalah Pondok Pesantren "Pondok Pesantren dan Ulama Hari Esok, Teori Mimpi Ibnu Khaldun”, Jakarta: Penerbit Perhimpunan Pengembangan Pondok Pesantren dan Masyarakat (P3M). p.19-20 
Dengan demikian dapat dipahami bahwa pesantren agar dapat berkembang survive dalam mengembangkan tadisi dengan cara menjadikan anak laki-laki sebagai penerus kepemimpinan kiai. Dalam kehidupan kultur pesantren kiai sebagai pengasuh membangun hubungan akrab antara kiai dan santri, kepatuhan santri kepada kiai, hidup zuhud, mandiri, tradisi ta'awun dan ukhuwah, disiplin dan siap menghadapi cobaan untuk mencapai tujuan.

Fenomena di dua Pesantren tersebut, memiliki kesamaan letak geografis, kebangsawanan, etnisitas, dan usia pesantren lebih setengah abad. Fenomena lain, ada kecenderungan dalam estafet kepemimpinan kiai berlangsung secara tiba-tiba dan terkesan kurang dipersiapkan. Misalnya, karena wafatnya pengasuh sebelumnya. Ada pula kecenderungan generasinya kurang memiliki keberanian mengambil kebijakan baru, dalam mengembangkan lembaga pesantren dengan alasan mempertahankan kemapanan yang sudah ada. Di lain pihak, adanya trend aktivitas kiai yang variatif di internal atau di eksternal dan di internal pesantrennya, keterlibatan ganda atau tidak dari figur kiai tersebut akan memberikan corak pada pola kepemimpinan yang diasuhnya.

Berdasar beberapa fenomena tersebut, maka penelitian tentang pergeseran pola kepemimpin kiai dalam mengembangkan lembaga pesantren menjadi menarik.

Tujuan penelitian ingin menganalisis dan menemukan pola kepemimpinan kiai, menganalisis dan menemukan pergeseran pola kepemimpinan kiai dan menganalisis dan menemukan dampak pergeseran pola kepemimpinan kiai pesantren.

Pada umumnya ada dua macam pola kepemimpinan kiai. Pertama; pola kepemimpinan individual; yaitu pola kepemimpinan kiai yang didasarkan atas kenyataan bahwa semua lahan dan komponen pesantren secara mutlak milik kiai. Hal tersebut berimplikasi pada tertutupnya kiai dari orang luar untuk mengusulkan berbagai usulan, ide strategik, dan konstruktif dalam mengembangkan lembaga pesantrennya di masa mendatang. Kedua; kepemimpinan kolektif yayasan; ketika kepemimpian individual dianggap berimplikasi kurang memadai disebabkan oleh salah satu kurangnya regenerasi yang memadai meneruskan kepemimpinan pendahulunya. Ada usulan agar pesantren keberlangsungannya perlu kepemimpinan kolektif yayasan dengan asumsi, agar tugas kiai ke depan menjadi agak ringan dalam menjalankan amanat kepemimpinan. 


\section{Mahfudz Sidiq}

Hal tersebut sejalan dengan kesimpulan dalam kata pendahuluan Azra, ${ }^{6}$ dalam buku "Bilik Bilik Pesantren”, terdapat kecenderungan, pesantren untuk melakukan konsolidasi organisasi kelembagaan khususnya pada aspek kepemimpinan dan manajemen. Secara tradisional kepemimpinan pesantren dipegang oleh satu atau dua orang kiai yang biasanya merupakan pendiri pesantren yang bersangkutan.

Beberapa pesantren modern telah mendirikan yayasan, yayasan ini menunjukkan transformasi pola kepemimpinan dari pola kepemimpinan individual kiai ke pola kepemimpinan kolektif yayasan. Apalagi realitanya di dalam pesantren terdapat madrasah maupun sekolah yang masing-masing ada pemimpinnya. Seharusnya kepemimpinan pesantren menjadi demokratis, tetapi kenyataannya masih belum memberikan kebebasan kepada guru/ustaz untuk menentukan pilihannya sendiri. Terutama ketika menyangkut pergantian kepala madrasah/sekolah misalnya, maka uji coba demokratisasi kepemimpinan pesantren masih belum berhasil. ${ }^{7}$

Dampak pergeseran pola kepemimpinan kiai meliputi kepemimpinan individual dan kolektif yayasan. Kepemimpinan individual; Pola kepemimpinan kiai sejak dulu sampai sekarang masih tetap menarik untuk diperbincangkan, karena warna keunikannya yang memancing siapapun yang ingin mencari tahu. Seperti pola kepemimpinan, yang dinyatakan Qomar $^{8}$, bahwa konteks kepemimpinan individual yang melekat pada diri kiai pada dasarnya tidak lepas dari intervensi masyarakat sendiri secara tulus, karena kelebihan dan keutamaan ilmu serta amal yang tidak dimiliki lazimnya orang lain, dan kebanyakan juga didukung oleh pesantren yang dipimpinnya. Oleh karena itu, kiai menjadi patron bagi masyarakat sekitar terutama yang menyangkut kepribadian utama.

Berdasarkan beberapa pendapat tersebut dapat disimpulkan bahwa pola, pergeseran, dan dampak kepemimpinan kiai, diperlukan pola kepemimpinan kiai individual dan atau kolektif

Mastuhu, ${ }^{9}$ menyatakan bahwa pergantian kepemimpinan pesantren menarik diamati. Terutama karena pesantren milik pribadi, estafet kepemimpinannya adalah dari-ke :

\footnotetext{
${ }^{6}$ Azyumardi Azra, Pengantar; dalam Nurcholish Madjid, tt., Bilik-Bilik Pesantren: Sebuah Potret Perjalanan, Jakarta Dian Rakyat., p. xxii

${ }^{7}$ Mujamil Qomar, tt. Mujamil Qomar, tt. Pesantren dari Transformasi Metodologi Menuju Demokratisasi Institusi, Jakarta: Erlangga, p. 166

${ }^{8}$ Mujamil Qomar, tt. Pesantren dari..... p. 28.

${ }^{9}$ Mastuhu, 1999. Memberdayakan Sistem Pendidikan Islam, Jakarta: Logos Wacana Ilmu, p. 95-96 
pendiri-anak-menantu-cucu-santri senior. Artinya ahli waris pertama adalah anak laki-laki dan dianggap sesuai oleh masyarakat untuk menjadi kiai, baik dari kesalihan maupun kedalaman ilmu agamanya. Jika tidak mungkin maka ahli waris kedua adalah menantu, dan sebagai ahli waris ketiga adalah cucu. Jika semuanya tidak maka ada kemungkinan dilanjutkan oleh mantan santri senior, dan bila pilihan ini yang terjadi, maka berakhirlah pesantren yang bersangkutan.

Kiai mempunyai otoritas mutlak. Ia pemimpin tunggal yang memegang kendali seluruh aktivitas pesantren, sehingga hampir-hampir tidak ada orang lain yang dihormati kecuali hanya kiai. Di pesantren, ia adalah tokoh yang melayani sekaligus melindungi para santri selama 24 jam. Dengan kekuasaannya seluruh ustaz apalagi santri baru tidak akan berani melakukan sesuatu tindakan kecuali mendapat restu kiai. Dengan demikian kiai mempunyai peran ganda yaitu sebagai pengasuh dan pemilik pesantren.

Pola kepemimpinan kiai inilah yang sesungguhnya memberikan corak hubungan di kalangan pesantren yang berlangsung dalam rentang waktu lama sejak berdirinya hingga sekarang dalam kebanyakan kasus. Dikarenakan pola kepemimpinan individual ini pula yang memberikan kesan bahwa pesantren adalah milik pribadi kiai, atau sebaliknya karena pesantren tersebut miliknya, maka kepemimpinan yang dijalankan adalah kepemimpinan individual. Kepemimpinan Kolektif Yayasan; Pola kepemimpinan kiai kharismatik yang menimbulkan sikap otoriter atau sekurang-kurangnya pseudo-demokratis dan berkuasa mutlak diramalkan tidak akan bertahan lama. Kaderisasi hanya terbatas pada keturunan (dzurriyah) menyebabkan tidak ada kesiapan menerima tongkat estafet kepemimpinan ayahnya. Karena tidak semua putra kiai mempunyai kemampuan, orientasi, dan kecenderungan sama dengan ayahandanya. Seringkali mereka melanjutkan ke sekolahsekolah umum dan perguruan-perguruan tinggi umum, tidak mau ke pesantren seperti skenario orang tuanya. Setelah lulus, mereka tidak memiliki kesiapan moral dan potensi untuk mengasuh pesantrennya, melainkan menjadi, misalnya; insinyur pertanahan, insinyur teknik, atau dokter ${ }^{10}$.

Dinyatakan Dhofier, ${ }^{11}$ usaha untuk meramalkan masa depan pesantren sangat sulit. Karena adanya kenyataan bahwa perubahan yang dilakukan oleh pesantren tersebut

\footnotetext{
${ }^{10}$ Mujamil Qomar, tt. Pesantren dari ..... p. 39-42

${ }^{11}$ Zamakhsyari Dhofier, 1985. Tradisi ....... p. 174 148 | Falasifa, Vol. 11 Nomor 1 Maret 2020
} 


\section{Mahfudz Sidiq}

melalui tahapan-tahapan yang pelan dan tidak mudah diamati. Selain itu, tidak semua pesantren melakukan perubahan yang sama. Secara umum peran kiai mengambil sikap lapang dalam menyelenggarakan modernisasi lembaga pesantren di tengah perubahan masyarakat Jawa, tanpa meninggalkan aspek positif dari sistem pendidikan Islam tradisional. Mereka juga berkeyakinan bahwa perubahan-perubahan harus diselenggarakan tanpa merusak aspek-aspek positif dari kehidupan pedesaan.

Untuk menjawab tiga tujuan penelitian, digunakan grand theory: Weber, ${ }^{12}$ mengkaji kewenangan pemimpin. Ia membagi tiga tipologi sistem kewenangan yaitu; traditional authority system, rational-legal authority system, dan charismatic authority system.

Rogers-Shoemaker ${ }^{13}$ mengatakan proses perubahan sosial secara berurutan terdiri: 1) invensi artinya proses di mana ide-ide baru diciptakan dan dikembangkan, 2) difusi artinya proses di mana ide baru itu dikomunikasikan, dan 3) konsekuensi artinya perubahan yang terjadi dalam sistem sosial sebagai akibat pengadopsian atau penolakan inovasi.

House $^{14}$, membagi empat perilaku kepemimpinan, 1) kepemimpinan direktif; memberi kesempatan pengikutnya mengetahui apa yang diharapkan dari mereka, 2) pemimpin suportif; ramah dan menunjukkan perhatian akan kebutuhan para pengikut, 3) pemimpin partisipatif; berkonsultasi dengan bawahan dan menerima saran mereka sebelum mengambil keputusan. 4) pemimpin berorientasi prestasi, menetapkan serangkaian sasaran dan mengharapkan bawahan untuk berprestas.

\section{METODE PENELITIAN}

Pendekatan penelitian ini adalah kualitatatif, jenis penelitian adalah phenomenology. Lokasi penelitian Pesantren Salafiyah Syafiiyah Sukorejo dan Pesantren Nurul Jadid. Data penelitian ini terdiri data primer dan sekunder. Penentuan informan didasarkan: 1) subjek cukup lama di pesantren, 2) subjek masih aktif atau tidak (alumni) di pesantren, 3) subjek mempunyai cukup waktu; dan 4) subjek memberikan informasi sebenarnya.

\footnotetext{
${ }^{12}$ George Ritzer, eighth edition, 2011. Sosiological Theory, New York: McGraw-Hill, a Business Unit of the McGraw-Hill Componies, Inc., 1221 Avence of the Americas. p. 29

${ }^{13}$ Everett M. Rogers dan F. Floyd Shoemaker, tt. Communication of Innovations, (terj.) Abdillah Hanafi, tt., Memasyarakatkan Ide-Ide Baru, Surabaya Indonesia, Usaha Nasional. p.16. Untuk selanjutnya disebut Everett M. Rogers dan F. Floyd Shoemaker, tt. Communication, ........

${ }_{14}$ Robbins, Stephen P., 2007. Organizational Behavior,, (terj.) Benyamin, Molan, Perilaku Organisasi, p. 448449 
Teknik pengumpulan data dengan wawancara mendalam, observasi berperan serta pasif, dan dokumentasi. Analisis data melalui data reduction, data display, dan verification. Pengecekan keabsahan berdasar pengujian kredibilitas; transferabilitas, dependabilitas, dan konfirmabilitas. Selain itu, menggunakan triangulasi sumber dan metode.

\section{PEMBAHASAN DAN HASIL PENELITIAN}

Pola Kepemimpinan Kiai Pesantren

Mastuhu, menjelaskan kehadiran pesantren di masyarakat tidak hanya sebagai lembaga pendidikan, tetapi juga sebagai lembaga penyiaran agama, dan sosial keagamaan. Pesantren berhasil menjadikan dirinya sebagai pusat gerakan pengembangan Islam ${ }^{15}$. Selain itu, alasan pokoknya dinyatakan Bruinessen ${ }^{16}$, untuk mentranmisikan Islam tradisional sebagaimana terdapat dalam kitab-kitab klasik yang ditulis berabad-abad yang dikenal di Indonesia sebagai kitab kuning.

Temuan penelitian di dua pesantren tentang pola kepemimpinan kiai sangat variatif dan memiliki karakteristik tersendiri yaitu pola: 1) kharismatik; 2) paternalistik; 3) kolegial; 4) demokratis; 5) pseudo-demokratis; 6) manajerial; dan 7) transformatif (inovatif). Implementasi pola tersebut tidak tunggal tetapi bisa dua atau tiga pola sekaligus dalam masa kepemimpinannya. Demikian pula temuan Madjid ${ }^{17}$, membagi kriteria sebagai tolok ukur pimpinan pesantren: 1) kharismatik; 2) personal; 3) Religio-feodalisme; 4) kecakapan teknis.

Beberapa kriteria kepemimpinan di pesantren dapat dijabarkan: Pertama, pola kepemimpinan kiai kharismatik-spiritual-keilmuan, indikasinya hidup sederhana seperti pakaian, fasilitas rumah, tempat tidur, dan keilmuannya sangat mendalam. Kedua, pola kepemimpinan paternalistik adalah kepemimpinan kebapakan dan menganggap santri seperti anak sendiri yang perlu bimbingan dan pengayoman.Diungkapkan Kartono, ${ }^{18}$ kepemimpinan paternalistik lebih identik dengan kepemimpinan kebapakan, cirinya: 1) menganggap bawahan sebagai manusia belum dewasa, atau anak sendiri, 2) terlalu melindungi; 3) jarang memberikan kesempatan bawahan untuk mengambil keputusan

\footnotetext{
${ }^{15}$ Mastuhu, 1994. Dinamika Sistem Pendidikan Pesantren, Suatu Kajian tentang Unsur dan Nilai Sistem Pendidikan Pesantren, Jakarta: Seri Indonesian-Netherlands Cooperation in Islamic Studies (INIS). p. 21

${ }^{16}$ Martin van Bruinessen, 1995. Kitab Kuning, Pesantren dan Tarekat, Bandung: Mizan., p. 17

${ }^{17}$ Nurcholish Madjid, tt. Bilik-Bilik Pesantren: Sebuah Potret Perjalanan, Jakarta Dian Rakyat., p.102-103

${ }^{18}$ Kartini Kartono, 1998. Pemimpin dan Kepemimpinan, Apakah Pemimpin Abanormal itu ? (edisi Baru), Jakarta. PT Raja Grafindo. p. 69 


\section{Mahfudz Sidiq}

sendiri; 4) hampir tidak memberikan kesempatan bawahan berinisiatif; 5) hampir tidak memberikan bawahan mengembangkan kreativitasnya, dan 6) bersikap maha tahu dan maha benar. Ketiga, pola kepemimpinan manajerialistik yang dikembangkan kiai menyempurnakan dan menata kelembagaan pesantren secara menyeluruh, kiai sukses melakukan pergeseran lembaga pesantren baik kuantitatif maupun kualitatif. Keempat, pola kepemimpinan Pseudo-demokratis, kepada para orang kepercayaannya menyebut "lepas tongar" (pura-pura memberi wewenang sebenarnya tetap membelenggu). Diungkapkan Burhanuddin ${ }^{19}$ kriteria Pseudo-demokratis tampaknya saja bersikap demokratis padahal sebenarnya bersikap otokratis. Kelima, pola kepemimpinan kharismatik-heredity, kiai mempunyai kharisma dalam kepengasuhannya karena sebab keturunan. Keenam, pola kepemimpinan transformatif (inovatif), sosok pemimpin yang memiliki indikasi visioner dan keilmuan.

Pergeseran pola kepemimpinan, menunjukkan bahwa di pesantren Sukorejo pergeseran pola kepemimpinan dalam mengembangkan lembaga pesantren : 1) dari pola kolegial terbatas bergeser ke kolegial-lebih luas; 2) dari kharismatik-keilmuan bergeser ke kharismatik-keilmuan-spiritual; 3) dari paternalistik bergeser ke pseudo-demokratis; 4) dari paternalistik bergeser ke manajerialistik; 5) dari kharismatik-keilmuan-spiritual bergeser ke kharismatik heredity; 6) dari kharismatik-heredity bergeser ke kharismatikkeilmuan-spiritual; 7) dari manajerialistik bergeser ke transformatif (inovatif); dan 8) dari pseudo-demokratis bergeser ke demokratis-spiritual (keagamaan).

Konsistensi pergeseran pola kepemimpinan dalam mengembangkan lembagapesantren, Sukorejo berawal dari salafiyah murni bergeser ke lembaga salafiyahkhalafiyah, dan Nurul Jadid sejak awal berdirinya konsisten pada lembaga salafiyahkhalafiyah, pergeseran keduanya melestarikan, menyempurnakan, membangun lembaga, dan membuat kebijakan baru sebagai wujud keterbukaan pesantren kepada dunia luar. Jika didialogkan dengan Rogers-Shoemaker, ${ }^{20}$ maka pergeseran kelembagaan ke dua pesantren, ada keserasian dengan proses perubahan sosial yaitu 1) invensi; proses di mana ide-ide baru diciptakan dan dikembangkan; 2) difusi; proses di mana ide-ide baru itu dikomunikasikan,

${ }^{19}$ Burhanuddin, 1994. Analisis Administrasi Manajemen Kepemimpinan Pendidikan, Jakarta: Bumi Aksara. p. 69.

${ }^{20}$ Everett M. Rogers dan F. Floyd Shoemaker, tt. Communication of Innovations, (terj.) Abdillah Hanafi, tt., Memasyarakatkan Ide-Ide Baru, Surabaya: Usaha Nasional. p.16 
dan 3) konsekuensi; perubahan yang terjadi dalam sistem sosial sebagai akibat pengadopsian atau penolakan inovasi.

Dampak pergeseran pola kepemimpinan kiai dari pertama sampai ke kiai empat pada pengembangan lembaga pesantren semakin berkembangnya lembaga secara kuantitatif maupun kualitatif, bertambahnya lembaga dari sebelumnya, dan regulasi kelulusan diniyah semakin diperketat, terpadunya keputusan rapat dan istikharah, dampaknya pengurus lebih hati-hati dalam menentukan hasil keputusannya, bertambahnya jumlah santri dan bangunan fisik, dibangunnya lembaga SMK 2 untuk menampung kebutuhan masyarakat sekitar, dan penguatan kualitas dosen dengan studi lanjut ke S2 dan S3.

Dampak pergeseran pola kepemimpinan pertama sampai kiai ke empat bersifat linier dari pola paternalistik, ke pola demokratis, dan terakhir ke pola transformatif, menunjukkan adanya: a) pengembangan lembaga pesantren yang sangat pesat; b) pola kepemimpinan kiai pertama perkembangan lembaga pesantren berkembang luar biasa, bahkan terjadi lompatan ekstrim yaitu memadukan pendidikan salafiyah (tradisional) dan pendidikan khalafiyah (modern); c) keberanian melakukan alih status kelembagaan dari swasta ke negeri, d) kiai mendirikan lembaga pendidikan dari TK sampai Perguruan Tinggi.

Berdasarkan beberapa temuan tersebut, dapat dirumuskan temuan konseptual penelitian sekaligus sebagai temuan keterbaruan (novelty) tentang pergeseran pola kepemimpinan kiai dalam mengembangkan lembaga pondok pesantren, sebagaimana skema berikut: 


\section{Mahfudz Sidiq}

Dzurriyyah dan Transcendent-Transformative Development.

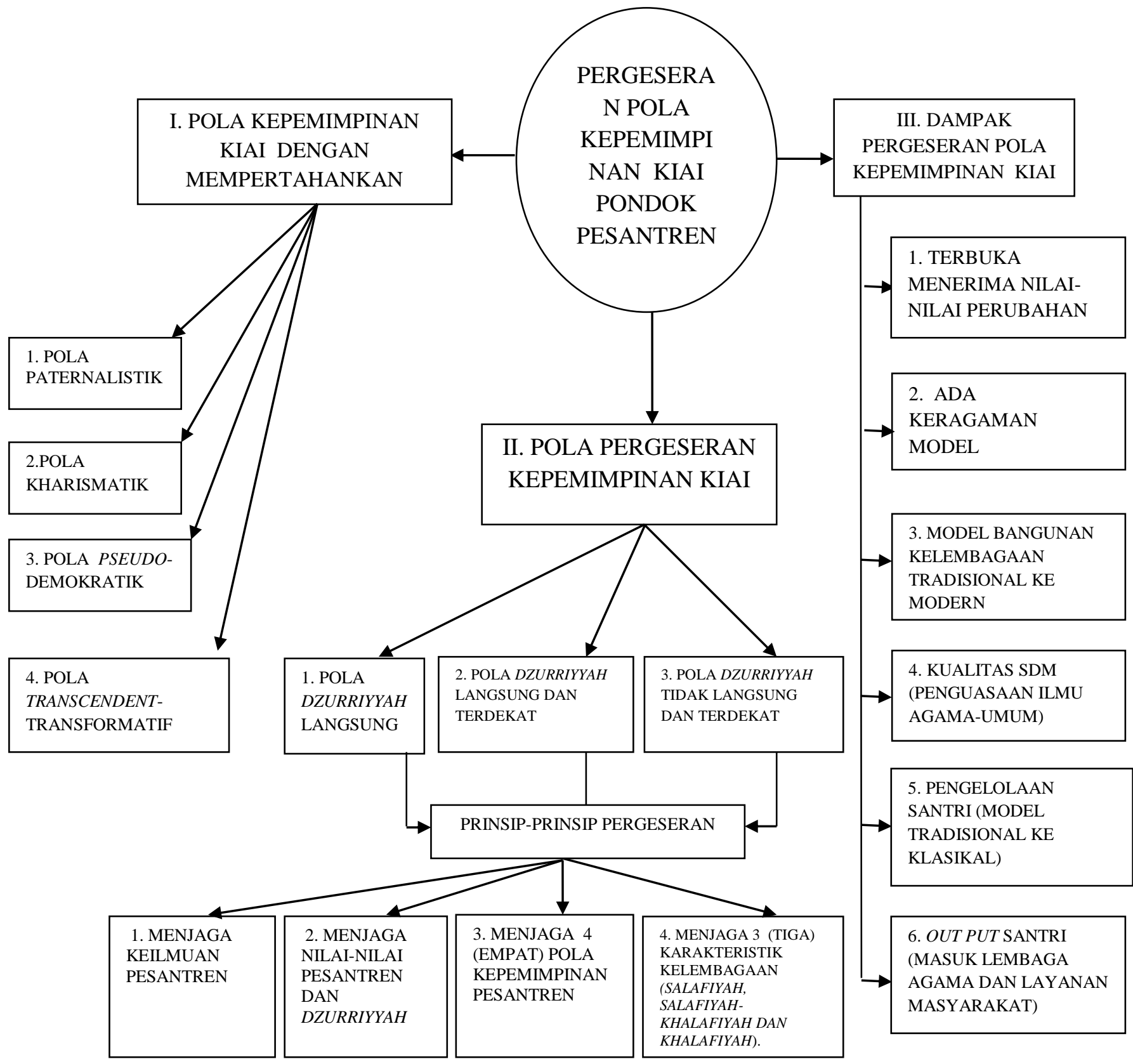

Berdasarkan skema tersebut, hasil penelitian ini dapat diopersionalkan berikut:

Pertama; Pola kepemimpinan kiai di dua pesantren adalah individual-berbasis yayasan (mendirikan yayasan), dengan menjaga dan mempertahankan keturunan (leader is 
born). Karakteristik kepemimpinan, menjaga pola kepemimpinan paternalistik, kharismatik, pseudo-demokratis, dan transcendent-transformative. Kedua; Pergeseran pola kepemimpinn kiai dalam mengembangkan pesantren mempertahankan : 1) pola dzurriyyah langsung; 2) pola dzurriyyah langsung dan terdekat; dan 3) pola dzurriyyah tidak langsung dan terdekat. Prinsip-prinsip kepemimpinan dzurriyyah mampu: a) menjaga keilmuan dan karakteristik pesantren; b) menjaga nilai-nilai karakteristik pesantren dan keluarga; c) menjaga nilai-nilai dan pola kepemimpinan yang karakteristiknya, paternalistik, kharismatik, pseudo-demokratis, dan transcendent-transformative; dan d) menjaga karakteristik model kelembagaan pesantren (salafiyah, salafiyah-khalafiyah, dan khalafiyah)., dan Ketiga; Dampak pergeseran pola kepemimpinan kiai dalam mengembangkan lembaga pesantren berdampak: 1) perilaku kepemimpinan lebih terbuka menerima nilai-nilai perubahan; 2) perkembangan model kelembagaan terjadi keragaman dari salafiyah, salafiyah-khalafiyah, dan khalafiyah; 3) perkembangan model bangunan pesantren awalnya dari kayu dan bambu sampai bangunan fisik modern; 4) perkembangan kualitas sumber daya manusia berupa penguasaan ilmu agama dan ilmu umum; 5) perkembangan pengelolaan santri dari model manajemen tradisional ke model klasikal; dan (6) output pesantren memasuki lembaga agama dan pelayanan masyarakat.

\section{PENUTUP}

\section{Kesimpulan}

Berdasarkan pembahasan dan hasil penelitian, maka dapat disimpulkan:

1) Pola kepemimpinan kiai di dua pesantren adalah individual-berbasis yayasan (mendirikan yayasan), dengan menjaga dan mempertahankan keturunan (dzurriyyah). Karakteristik kepemimpinan kiai, menjaga pola kepemimpinan paternalistik, kharismatik, pseudo-demokratis, dan transcendent-transformative.

2) Pergeseran pola kepemimpinn kiai mempertahankan : (1) pola dzurriyah langsung; (2) pola dzurriyyah langsung dan terdekat; dan (3) pola dzurriyyah tidak langsung dan terdekat. Prinsip-prinsip kepemimpinan dzurriyyah adalah mampu: a)menjaga keilmuan dan karakteristik pesantren; b) menjaga nilai-nilai karakteristik pesantren dan keluarga; c) nilai-nilai dan pola kepemimpinan yang karakteristiknya, paternalistik, kharismatik, pseudo-demokratis, dan transcendent-transformative; dan d) menjaga model kelembagaan (salafiyah, salafiyah-khalafiyah, dan khalafiyah). 


\section{Mahfudz Sidiq}

3) Dampak pergeseran pola kepemimpinan kiai meliputi: (1) perilaku kepemimpinan lebih terbuka menerima nilai-nilai perubahan; (2) perkembangan model kelembagaan terjadi keragaman dari salafiyah, salafiyah-khalafiyah, dan khalafiyah; (3) perkembangan model bangunan fisik awalnya kayu sampai bangunan modern; (4) perkembangan kualitas sumber daya manusia berupa penguasaan ilmu agama dan ilmu umum; (5) perkembangan pengelolaan santri dari model manajemen tradisional ke model klasikal; dan (6) output pesantren memasuki lembaga agama dan pelayanan masyarakat.

\section{Implikasi penelitian}

Implikasi dari temuan penelitian ini dapat dijabarkan sebagai berikut:

Pertama; Implikasi yang berkaitan dengan pola kepemimpinan kiai. Hasil penelitian ini mengelaborasi tiga kewenangan pemimpin Weber yaitu; traditional authority system, rational-legal authority system, dan charismatic authority system. Dalam konteks sekarang setidaknya di dua pesantren berdasar Weber tersebut kurang memadai lagi, karena temuan menunjukkan pola kepemimpinan individual kiai-berbasis yayasan, konsisten dengan pola kharismatik, tetapi variatif dari satu pola ke pola lain. Dengan kata lain temuan ini sebagai konsep baru, karena kepemimpinan kiai menggunakan berbagai pola. Kepemimpinan kiai sekarang pola kharismatik-spiritual-keilmuan, paternalistik, pseudo-demokratis, dan kepemimpinan transformatif dengan perilaku keteladanan.

Kedua; Implikasi yang berkaitan dengan pergeseran pola kepemimpinan kiai dalam mengembangkan lembaga. Temuan penelitian secara teoretis berimplikasi pada pengembangan Rogers dan Soemaker, dalam konteks sekarang setidaknya berimplikasi pada: 1) pengembangan ide-ide baru (invensi); 2) ide-ide baru itu dikomunikasikan (difusi); 3) perubahan terjadi sebagai akibat adopsi atau penolakan inovasi (konsekuensi).

Ketiga; Temuan penelitian berimplikasi pada pengembangan teori House (path goal) yaitu: 1) kepemimpinan direktif; memberi kesempatan pengikutnya mengetahui apa yang diharapkan, 2) pemimpin suportif; menunjukkan perhatian kebutuhan para pengikut; 3) pemimpin partisipatif; berkonsultasi dengan bawahan dan menerima saran sebelum mengambil keputusan; 4) pemimpin berorientasi prestasi; menetapkan sasaran yang menantang anggota berprestasi.

\section{DAFTAR PUSTAKA}


Azra, Azyumardi, 2012. Pendidikan Islam Tradisi dan Modernisasi di tengah Tantangan Milenium III, Jakarta: UIN Press.

Bruinessen, Martin van, 1995. Kitab Kuning, Pesantren dan Tarekat, Bandung: Mizan.

Everett M. Rogers dan F. Floyd Shomaker, tt. Communication of Innovations, (terj.) Abdillah Hanafi, tt., Memasyarakatkan Ide-Ide Baru, Surabaya Indonesia, Usaha Nasional.

Henderson, AM and Parsons, Talcott, (translated) 1947., Max Weber: The Theory of Social and Economic Organization, The Free Press, Glencoe, Illinois. New York, Inc Oxford University Press.

Jonge, Huub de, Madura Dalam Empat Zaman: Pedagang, Perkembangan Ekonomi dan Islam, Jakarta: PT. Gramedia, 1989.

Madjid, Nurcholish, tt. Bilik-Bilik Pesantren: Sebuah Potret Perjalanan, Jakarta: Dian Rakyat.

Mastuhu, 1994. Dinamika Sistem Pendidikan Pesantren, Suatu Kajian tentang Unsur dan Nilai Sistem Pendidikan Pesantren, Jakarta: Seri Indonesian-Netherlands Cooperation in Islamic Studies (INIS).

Miles, Matthew B. dan A. Mechael Huberman, 1984. Qualitative Data Analysis (terj.) Tjetjep Rohendi Rahidi, 2007, Analisis Data Kualitatif, Buku Sumber tentang MetodeMetode Baru, Jakarta: UI Press.

Qomar, Mujamil, tt. Pesantren: Dari Transformasi Metodologi Menuju Demokratisasi Institusi, Jakarta: Erlangga.

Suprayogo, Imam, 2007. Kiai dan Politik: Membaca Citra Politik Kyai, Malang UIN Malang: Press.

Wahid, Abdurrahman, 1978. Beberapa Pemikiran tentang Kepemimpinan dalam Pengembangan: Jakarta: Pendidikan dan Latihan Pembinaan Pondok Pesantren seIndonesia di PKP Cibubur.

Yukl, Gary, 2001. Leadership on Organization (Terj) Kepemimpinan dalam Organisasi, Edisi kelima, Supriyanto, Budi, Jakarta: PT Indeks.

Dhofier, Zamakhsyari, 1985. Tradisi Pesantren: Studi Tentang Hidup Kiai, Jakarta: LP3ES. 